Ririen Titi Yuliarti, Ismu Suharsono Suwelo, Sri Harini Soemartono

Indonesian Journal of Dentistry 2008; 15 (2):163-168

$\mathrm{http} / / \mathrm{www} . \mathrm{fkg}$.ui.edu

Fakultas Kedokteran Gigi

Universitas Indonesia

ISSN 1693-9697

\title{
KANDUNGAN UNSUR FLUOR PADA EMAIL GIGI TETAP MUDA DENGAN TUMPATAN SEMEN IONOMER KACA VISKOSITAS TINGGI
}

\author{
Ririen Titi Yuliarti, Ismu Suharsono Suwelo, Sri Harini Soemartono \\ Department of Pediatric Dentistry, Faculty Dentistry, University of Indonesia
}

\section{Keywords: \\ Fluoride, Enamel of immature teeth, Fuji IX and Ketac Molar.}

\begin{abstract}
The purpose of this study was to determine the fluoride content differences in enamel of immature teeth with Glass Ionomer Cement Fuji IX and Ketac Molar filling.The subject for this study was 21 immature premolars teeth, and each tooth divided into 2 parts. The first part filled with Fuji IX (Fuji IX ART, GC) and the second part filled with Ketac Molar (Ketac Molar ART, MI, 3M ESPE), so the samples were 21 Energy Dispersive X-Ray Spectrophotometry analysis of Fuji IX and 21 Energy Dispersive X-Ray Spectrophotometry analysis of Ketac molar. The measurement was done to the fluoride content in enamel of immature teeth using Energy Dispersive X-Ray Spectrophotometry in percentage.This study using t-test, exhibited differences but no significant from the percentage of delta the fluoride content in enamel of immature teeth with Fuji IX and Ketac Molar filling $(\mathrm{t}=1,953 \mathrm{p}>0.05)$.
\end{abstract}

\section{Pendahuluan}

Dengan adanya kemajuan tehnologi saat ini, maka bahan restorasi kedokteran gigi juga terus-menerus mengalami kemajuan dalam segi estetis, kekerasan dan kekuatan bahan terhadap tekanan pengunyahan, serta kekuatan adhesi bahan terhadap struktur gigi. Bahan yang sering digunakan untuk merestorasi baik gigi sulung maupun gigi tetap dalam praktek kedokteran gigi adalah bahan restorasi adesif sewarna gigi. Bahan restorasi sewarna gigi yang banyak beredar dipasaran adalah Glass Ionomer Cement (Semen Ionomer Kaca=SIK), kompomer dan resin komposit.

Dari segi estetis, resin komposit lebih unggul namun bahan ini tidak mengandung fluor. SIK lebih banyak mengandung fluor dibandingkan kompomer dan tidak memerlukan 
etsa asam, sehingga relatif lebih aman digunakan untuk merestorasi gigi sulung maupun gigi tetap muda. Pelepasan fluor dari bahan restorasi dapat membantu proses remineralisasi email dan mencegah karies gigi. ${ }^{1}$

SIK terdiri dari bubuk kalsium fluoroalumino silikat gelas yang mengandung fluor sekitar 12-18 \% dengan cairan asam poliakrilik kopolimer dan asam tartar. ${ }^{2,3,4}$ SIK Konvensional pertama kali diperkenalkan oleh Wilson dan Kent pada tahun 1972 sebagai semen yang mempunyai kelebihan dari pada semen silikat dan semen polikarboksilat. ${ }^{5}$ Bahan SIK konvensional kemudian dikembangkan menjadi SIK viskositas tinggi pada awal tahun 1990 yang didukung WHO sebagai jawaban atas kebutuhan akan bahan tumpatan dalam terapi restorasi otomatis. ${ }^{6}$ Viskositas tinggi berarti mempunyai kekentalan yang tinggi dengan flow yang rendah. ${ }^{7}$ Viskositas tinggi SIK diperoleh dari hasil penambahan asam poliakrilat pada bubuk dan distribusi butiran partikelnya lebih halus. ${ }^{8}$

Email terdiri dari 96\% bahan anorganik, 4\% bahan organik, air dan jaringan fibrosa. Bahan anorganik terdiri dari beberapa juta kristal hidroksiapatit. Tiap unit kristal terdiri dari kalsium, phosphat dan ion hidroksil dengan formula $\left.\left(\mathrm{Ca}_{10}\left(\mathrm{PO}_{4}\right)_{6}(\mathrm{OH})_{2}\right)\right)^{9,10}$ Sisanya adalah $\mathrm{CO}_{3}, \mathrm{Mg}, \mathrm{Na}, \mathrm{K}, \mathrm{Fe}, \mathrm{Cl}$, dan Fluor sekitar $0,02 \%{ }^{5}$ Email sebagian besar mengandung kristal hidroksiapatit sehingga dapat menyerap fluor yang dilepaskan oleh SIK dengan membentuk suatu ikatan fluoroapatit yang lebih tahan terhadap asam. ${ }^{11}$

Reaksi setting SIK merupakan reaksi asam basa antara bubuk aluminosilikat gelas dengan asam poliakrilat. Polyacid (asam poliakrilik, asam itakonat dan asam tartar) kemudian bereaksi dengan gelas, sehingga melepaskan ion fluor. Ion ini merupakan kompleks metal fluor, yang kemudian bereaksi dengan polianion untuk membentuk salt gel matriks. Ion $\mathrm{Al}^{3+}$ menyebabkan matrix resisten terhadap flow. ${ }^{12}$ Asam poliakrilik yang telah menempel pada stuktur email gigi kemudian berikatan dengan ion kalsium apatitit dan ion fosfat pada email dan dentin. ${ }^{13}$
Secara mekanisme fisikokimia, fluor yang diserap email dari bahan restorasi yang mengandung fluor akan menghambat demineralisasi. Gugus $\mathrm{OH}$ dalam kristal hidroksiapatit struktur gigi dapat disubstitusi oleh fluor yang dilepaskan dari bahan restorasi yang mengandung fluor, kemudian menjadi fluoroapatit dengan formula $\mathrm{Ca}_{10}\left(\mathrm{PO}_{4}\right) \mathrm{F}_{2}$ yang lebih resisten terhadap asam. ${ }^{14}$

Pada saat gigi erupsi, proses mineralisasi email belum selesai dan akan berlanjut sampai kira-kira 2-3 tahun setelah erupsi. Selanjutnya proses demineralisasi dan mineralisasi terjadi terus-menerus sejak email selesai terbentuk, sebagai proses maturasi. ${ }^{15}$ Mahkota gigi yang sudah tumbuh ke rongga mulut dan maturasinya belum sempurna, akan sangat peka terhadap perubahan mineral dalam rongga mulut. Bila pada tahap maturasi email terdapat fluor didalam rongga mulut, maka ion fluor dengan cepat berikatan dengan kristal hidroksiapatit membentuk fluoroapatit yang lebih tahan terhadap pelarutan asam. Email bagian dalam, yang pertama larut, sedang bagian permukaan sukar larut karena kandungan fluoridanya lebih tinggi. ${ }^{16}$ Reaksi ini sebagian menjelaskan peran fluor dalam pencegahan karies saat proses karies diawali oleh demineralisasi email. Reaksi remineralisasi sangat diperkuat oleh adanya keberadaan fluor. ${ }^{17}$

Ada 2 mekanisme pelepasan fluor, yaitu pelepasan reaksi jangka pendek dan jangka panjang. Reaksi jangka pendek, berkaitan dengan reaksi awal karena proses maturasi setelah setting, terjadi pelepasan fluor tertinggi pada 24-48 jam pertama setelah terpapar fluor, kemudian menurun secara konstan setelah beberapa minggu atau beberapa bulan. Pada reaksi jangka panjang, pelepasan fluor lebih rendah dan stabil sesuai dengan keseimbangan proses difusi. ${ }^{6,18}$ Sedangkan dari penelitian Freedman, pada hari ke 6 dan ke 7, tampak adanya peningkatan jumlah pelepasan fluor dari tumpatan SIK. Kelebihan dari SIK, mampu mengisi kembali fluor melalui paparan sumber fluor dari luar, kemudian melepaskan kembali ke lingkungan mulut. ${ }^{19}$ Penelitian lainnya yang meneliti efek kariogenik setelah penumpatan 
SIK, memperoleh hasil rerata penyerapan fluorida tertinggi setelah satu minggu. ${ }^{6}$

Komposisi SIK Fuji IX dan SIK Ketac Molar pada dasarnya sama. Komposisi Ketac Molar terdiri dari Ca, La, Al fluorosilicate glass dan pigmen. Cairannya terdiri dari asam polikarboksilat, asam tartar dan air. Hasil pencampuran antara bubuk dan cairan bahan ini mempunyai karakteristik berupa peningkatan stabilitas terhadap abrasi. ${ }^{20}$ Kandungan Fuji IX terdiri dari fluor, calsium, strontium, dan aluminium dengan cairan asam poliakrilik. Unsur terbanyak adalah kalsium. Pelepasan $\mathrm{Sr}$ dari Fuji IX kedalam air yang terdeionisasi tergantung $\mathrm{pH}$. Makin rendah $\mathrm{pH}$, makin besar pelepasan fluor. Dengan adanya $\mathrm{Sr}$ yang menggantikan unsur $\mathrm{Ca}$, dapat terjadi $\mathrm{Sr}$ Hidroksiapatit yang membantu proses remineralisasi, terutama pada pasien dengan aktifitas karies yang tinggi. ${ }^{21}$ Berdasarkan hasil penelitian oleh ESPE, didapat bahwa Ketac Molar mempunyai setting time yang lebih cepat, kekerasan permukaan lebih tinggi dan radiopacity lebih rendah dibandingkan Fuji $\mathrm{IX}^{20}$

Pada suatu penelitian secara in vivo menunjukkan bahwa unsur fluor dari tumpatan SIK yang diserap email, efektif menghambat demineralisai email gigi dalam larutan karies buatan dengan $\mathrm{pH}$ 4,8. Hasil penelitian ini adalah frekuensi dan perluasan dinding lesi karies artificial disekeliling restorasi berkurang dengan adanya kemampuan email menyerap fluor sehingga berpengaruh terhadap perkembangan karies di sekeliling restorasi. ${ }^{1}$

SIK konvensional mengalami modifikasi menjadi SIK dengan viskositas tinggi yang dirancang sebagai alternatif tumpatan amalgam untuk restorasi preventif gigi posterior. Bahan ini berguna untuk tehnik Atraumatic restorative Treatment (ART). ${ }^{6}$ SIK dengan viskositas tinggi telah banyak beredar dipasaran, antara lain adalah Fuji IX dan Ketac Molar. Dengan kemampuannya melepaskan fluor, dan aplikasinya yang mudah, SIK menjadi bahan restorasi pilihan untuk merawat gigi anak, perawatan karies dini dan penderita dengan insidens karies tinggi. ${ }^{2}$ Tujuan Penelitian ini, untuk mengetahui perbedaan kandungan unsur fluor antara email gigi tetap muda dengan tumpatan Fuji IX dan email gigi tetap muda dengan tumpatan Ketac Molar. Pengamatan dilakukan dengan alat Energy Dispersive $X$-ray Spectrophotomrtry (EDS) yang merupakan bagian dari SEM (scanning electron microscope) dengan LEICA S240. Alat ini dihubungkan dengan komputer dan hasilnya berupa angka dan grafik. SEM digunakan untuk melihat secara fisik, sedangkan alat EDS cenderung digunakan untuk mendeteksi secara kimiawi. $^{22}$

\section{Bahan dan Cara}

Gigi premolar muda yang baru dicabut untuk keperluan perawatan ortodonsi, dibersihkan dan disimpan dalam larutan salin ( $\mathrm{NaCL}$ 0,9\%). Setiap gigi di preparasi pada permukaan mesio oklusal dan disto oklusal dengan bentuk kavitas klas I sedalam sekitar 1 $\mathrm{mm}$, menggunakan round bur dengan handpiece kecepatan tinggi. Kavitas pertama, diolesi kondisioner kemudian ditumpat dengan Fuji IX dan dilapisi varnish. Kavitas kedua, diolesi konditioner, kemudian di tumpat dengan Ketac Molar dan di lapisi dengan varnish. Setelah semua gigi premolar muda di tumpat, kemudian di simpan kembali kedalam larutan salin untuk diperiksa kandungan fluor pada hari ke tujuh.

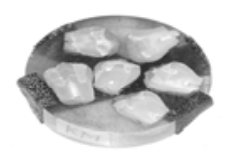

Gambar 1. Gigi dengan Tumpatan dan Sudah Dimounting

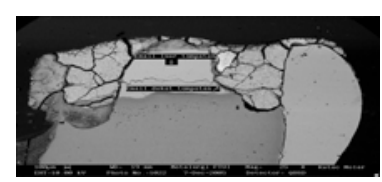

Gambar 2. Area PemeriksaanKandungan Unsur Flour pada Email Gigi Tetap Muda 


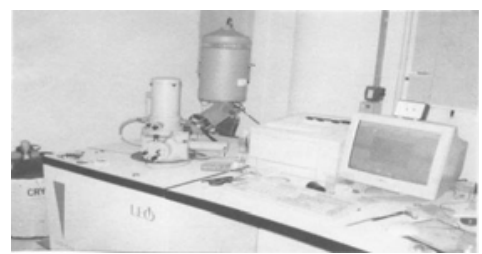

Gambar 3. Alat EDS dan SEM yang Dihubungkan dengan Komputer

Semua gigi dipersiapkan untuk diamati kandungan unsur fluor pada email gigi premolar muda dengan alat EDS. Persiapan awal yang dilakukan adalah semua gigi yang sudah di tumpat, di mounting dengan bahan resin dan di poles agar dapat dipotong (Gambar 1). Semua mounting dipotong arah mesial-distal, kemudian dilakukan coating dengan menggunakan tembaga dan di vakum dengan alat vakum untuk menghilangkan kandungan air di dalam gigi. Tahap selanjutnya, mounting dimasukkan dalam alat SEM, untuk menentukan lokasi jaringan email yang ada tumpatan dan dilakukan penyinaran dengan alat EDS. Setiap gigi ditentukan area penyinaran pada email, 3 kali di tepi tumpatan Fuji IX, 3 kali di tepi tumpatan Ketac Molar dan, 3 kali diluar tumpatan, sehingga didapatkan 189 data (gambar 2). Arah sinar X-ray harus tegak lurus terhadap permukaan sampel yang diteliti. Hasil pemeriksaan dengan EDS (Gambar 3) dalam satuan ratio (\%), menunjukkan banyaknya kandungan fluor pada email gigi premolar muda yang ditumpat dengan Fuji IX dan yang ditumpat dengan Ketac Molar. Metode yang digunakan adalah double blind. Penelitian ini dilakukan di jurusan Metalurgi Fakultas Tehnik Universitas Indonesia. (Gambar 1, 2, 3) diambil dari Laboratorium Metalurgi Fakultas Teknik Universitas Indonesia. 2005. Untuk mengetahui perbedaan kandungan unsur fluor antara email gigi tetap muda dengan tumpatan Fuji IX dan email gigi tetap muda dengan tumpatan Ketac Molar, dilakukan uji-t dengan batas kemaknaan $\mathrm{p}=0,05$

\section{Hasil}

Dari pengamatan dengan EDS, diperoleh hasil berupa grafik tanpa tumpatan, grafik dengan tumpatan Fuji IX, grafik dengan tumpatan Ketac Molar dan nilai kandungan unsur fluor pada email gigi tetap muda dalam $\%$. Contoh gambar lokasi pengamatan jaringan email dengan alat EDS dapat dilihat pada gambar 2.

Tabel 1. Uji t dari Selisih Kandungan Unsur Fluor antara Email Gigi Tetap Muda Tanpa Tumpatan dan dengan Tumpatan Fuji IX dan Ketac Molar

\begin{tabular}{llcllr}
\hline \multirow{2}{*}{ Tumpatan } & \multicolumn{1}{c}{$\Delta$} & Kisaran & $\mathrm{t}$ & df & $\mathrm{p}$ \\
\cline { 2 - 3 } & Rerata $\pm \mathrm{SB}$ & & & & \\
\hline Fuji IX & $2.09 \pm 0.75$ & $1.03-3.24$ & & \\
Ketac Molar & $2.34 \pm 0.36$ & $1.08-0.96$ & & \\
\hline
\end{tabular}

Keterangan : $\mathbf{t}=$ Nilai Uji, $\quad \mathbf{S B}=$ Simpang Baku $\mathbf{p}=$ Nilai Signifikan $\mathbf{d f}=$ degree of freedom $\Delta=$ Selisih kandungan unsur fluor (\%) antara tanpa dan dengan tumpatan Fuji IX dan Ketac Molar

Berdasarkan data pada tabel 1, secara statistik terlihat ada perbedaan yang tidak bermakna antara kandungan unsur fluor pada email gigi tetap muda dengan tumpatan Fuji IX dan email gigi tetap muda dengan tumpatan $\operatorname{Ketac}$ Molar $(\mathrm{t}=1,953 \mathrm{p}=0,065)$.

\section{Pembahasan}

Pada penelitian ini menggunakan dua bahan tumpatan Semen Ionomer Kaca Viskositas tinggi, karena bahan ini sudah banyak beredar di pasaran dan sudah banyak digunakan secara luas untuk menumpat gigi pada anak. Beberapa penelitian menunjukkan bahwa adanya pelepasan unsur fluor dari bahan tumpatan ini dapat membantu proses remineralisasi email dan mencegah karies gigi. ${ }^{1}$ Dengan demikian, SIK sangat baik digunakan untuk anak dengan resiko karies yang tinggi dan karena aplikasinya yang mudah, juga baik untuk anak yang kurang kooperatif. ${ }^{2}$

Subyek yang digunakan pada penelitian ini adalah gigi tetap muda, karena pada gigi tetap muda proses mineralisasinya belum selesai. Dalam literatur dikatakan bahwa proses mineralisasi masih terus berlanjut sampai 
sekitar 2-3 tahun setelah gigi erupsi, sebagai proses maturasi email. ${ }^{15}$ Bila pada tahap ini terdapat ion fluor yang diserap email dari bahan restorasi, maka dapat menghambat demineralisasi. ${ }^{17}$

Bentuk dan dalamnya kavitas serta jenis mata bur yang digunakan tidak mempengaruhi hasil penelitian, karena yang akan diamati pada penelitian ini hanya banyaknya kandungan unsur fluor pada email gigi tetap muda. Hal ini tidak dapat dilakukan bila yang akan diteliti adalah penetrasi bahan tumpatan kedalam struktur gigi.

Gigi yang digunakan disimpan dalam larutan salin sebelum dan sesudah penumpatan. Tujuannya agar gigi tetap terjaga dalam kondisi fisiologis, karena larutan ini mempunyai $\mathrm{pH}$ yang netral. Bila meggunakan larutan dibawah $\mathrm{pH}$ netral, maka akan terjadi demineralisasi email dan peningkatan pelepasan fluor sehingga dapat mempengaruhi hasil penelitian terhadap kandungan unsur fluor pada email gigi tetap muda.

Kondisi gigi dalam penelitian ini harus bebas karies, agar tidak terjadi proses demineralisasi yang dapat mempengaruhi hasil penelitian terhadap kandungan unsur fluor antara email gigi tetap muda yang ditumpat Fuji IX dan email gigi tetap muda yang ditumpat Ketac Molar.

Proses mounting, coating dan vakum perlu dilakukan sebelum pengamatan dengan alat EDS. Hal ini disebabkan jenis sampel yang digunakan adalah komponen organik yang cukup banyak mengandung air, sehingga memerlukan proses vakum untuk menghilangkan kandungan airnya agar dapat diamati dengan alat SEM dan EDS.

Pengukuran kandungan unsur fluor pada email gigi tetap muda pada penelitian ini menggunakan alat EDS. Alat EDS adalah suatu sistem yang ideal untuk menganalisis banyaknya unsur yang terdapat dalam suatu material baik secara kualitatif maupun kuantitatif serta hasilnya berupa grafik dan nilainya dalam persen. ${ }^{22}$ Hasil yang diperoleh adalah tiga macam grafik, tanpa tumpatan, dengan tumpatan Fuji IX , dengan tumpaqtan Ketac Molar dan besarnya kandungan unsur fluor serta unsur-unsur kimia lainnya ikut.terdeteksi.

Pada penelitian ini pengukuran kandungan fluor dengan alat EDS dilakukan pada hari ke tujuh. Hal ini berdasarkan beberapa penelitian terdahulu yang menyatakan bahwa pada hari ke tujuh tampak terjadi peningkatan pelepasan fluor dari tumpatan SIK. ${ }^{19}$

Dari pengukuran EDS, didapatkan persentase jumlah kandungan unsur fluor pada email gigi tetap muda dengan tumpatan kedua bahan SIK viskositas tinggi yang diasumsikan sesudah ditumpat, terjadi peningkatan dibandingkan kandungan unsur fluor tanpa tumpatan yang diasumsikan sebagai sebelum ditumpat. Hal ini membuktikan kemampuan SIK melepaskan fluor yang dapat melindungi struktur gigi disekitarnya dan gigi didekatnya terhadap karies dan demineralisasi.

Hasil uji t dari nilai delta kandungan unsur fluor antara kedua bahan tersebut menunjukkan perbedaan yang tidak bermakna, kemungkinan kedua bahan tumpatan yang digunakan pada penelitian ini adalah termasuk SIK dengan viskositas tinggi yang mempunyai komposisi dasar yang hampir sama. Perbedaannya, pada Ketac Molar ditambahkan unsur lanthanum yang berguna untuk meningkatkan ketahanan terhadap abrasi dan tekanan kunyah $^{20}$, sedangkan pada Fuji IX ditambahkan unsur Sr untuk membantu proses remineralisasi. ${ }^{21}$

Dari hasil penelitian yang telah dilakukan terhadap kandungan unsur fluor pada email gigi tetap muda dengan tumpatan Fuji IX dan Ketac Molar menggunakan alat EDS, didapatkan perbedaan yang tidak bermakna antara kandungan unsur fluor pada email gigi tetap muda dengan tumpatan Fuji IX dan email gigi tetap muda dengan tumpatan Ketac Molar.

\section{Daftar Pustaka}

1. Attar N dan Onen A. Artificial Formed CariesKandlikgan UnssiopuorAround Esthetic Restorative Material. J. Ped. Dent. 2002; 26: 288-94.

2. Wilson AD dan Mc Leani JW. Glass Ionomer Cement. Chicago Quentescence Pub. 1998: 2130, 88-98. 
3. Baratieri LN. Advance Operative Dentistry. $2^{\text {nd }}$ ed. Rio de Janeiro. Quintessence Editoria Ltd. 1993: 167-240.

4. Suweto IS. Penggunaan Bahan Sewarna Gigi Untuk Pencegahan Karies dan Restorasi Gigi Anak. JKGUI Jakarta: FKG-UI Press, 1995: 2(3)33-9.

5. Schour I. The structure of enamel. In Noye's oral histology and embryology. $8^{\text {th }}$ ed. Philadelphia, Lea \& Febiger, 1960: 88-113.

6. Davidson CL dan Mjor IA, Advances in Glass Ionomer Cement. Chicago Quintessence Pub. 1999: 15-46, 121-33.

7. Viscosityat: http://www.spacegrant.hawaii.edu/ class_acts/ViscosityTe.html. 1996

8. Frankenberger R, Sindel J dan Kramer N. Viscous Glass Ionomer cements; A new alternative to amalgam in primary dentition. Quint Int. 1997; 28(10): 667-75.

9. Avery JK. Essentials of Oral Histology and Embriology. St.Louis. Mosby Co. 1992: 84-92.

10. Avery JK. Oral development histology. $2^{\text {nd }}$ ed. New York. Thieme Medical Pub. Inc. 1994: 282-95, 228-40.

11. De Moor RJG dan Verbeeck RMH. Effect of acetic acid on the fluoride release profiles of restorative Glass Ionomer cement. Dental Material. 1998. 14; 261-8.

12. Hickel RA dan Folwaczny M. Various Forms of Glass Ionomer and Compomers. J. Op.Dent. 2001; 6:177-90.
13. Mount GJ. Preservation and Rectoration of Tooth Structure. London. Mosby Co. 1998: 69-92.

14. Karantis P dan Antoniades MH, Pahini ST et al: Fluoride Release from Three Glass Ionomer, A Compomer and A Composite Resin in Water, Artifisial Saliva and Lactic Acid. J.Op.Dent. 2000; 25: 20-5.

15. Sumartono SH. Masalah karies gigi anak. Buku Naskah Ilmiah KPPIKG-IX. 1991: 392-7.

16. Thylstrup A dan Fejerskov O. Textbook of Cariology, Copenhagen, Munksgaard, 1986: 206-10, 214, 181-201.

17. Ten Cate AR. Oral histology, development, structure and function, St.Louis: Mosby, 1980: 122-37, 194-217.

18. Fejerskov O dan Kidd E. Chemical interactions between the tooth and oral fluids. In Dental Caries. Copenhagen, Munksgaard. 2003: 50-60.

19. Freedman R dan Dietenderfer KE. Effects of daily fluoride exposures on fluoride realease by GIC-Based Restoratives. J Op. Dent 2003; 28(2)92: 178-85.

20. Ketac Molar Quick. Clinical Research at: http://multimedia.mmm.com/mws/mediawebser ver.dyn?0000008vG Col6Poa6PooojBy\&0000o m- $6 / 2000$.

21. Mount GJ. Preservation and Rectoration of Tooth Structure. London. Mosby Co. 1998: 6992.

22. Goodhew PJ dan Humprey FJ. Electrone microscopy and analysis. $2^{\text {nd }}$ ed. London: Taylor $\&$ Francis. 


\section{LAMPIRAN}

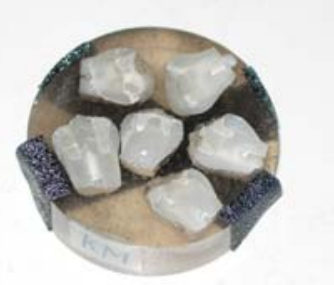

Gambar 1.Gigi dengan Tumpatan dan Sudah Dimounting

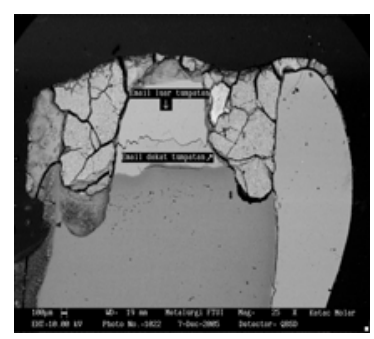

Gambar 2. Area Pemeriksaan Kandungan Unsur Fluor pada Email Gigi Tetap Muda

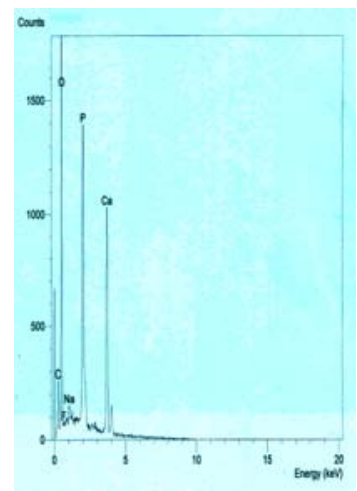

B

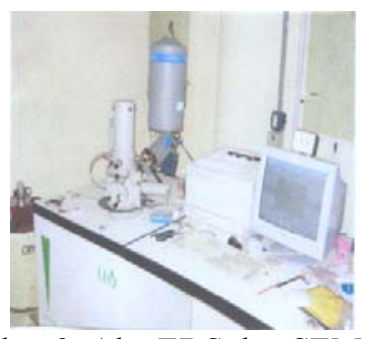

Gambar 3. Alat EDS dan SEM yang Dihubungkan dengan Komputer

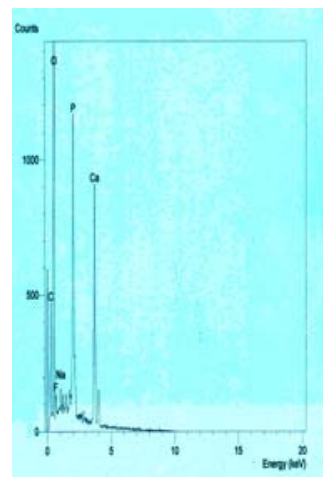

A

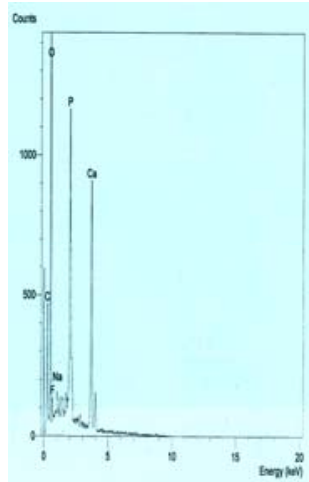

C

Gambar 4. Grafik Hasil Pengamatan Kandungan Unsur Fluoride pada Email Gigi Tetap Muda dengan menggunakan EDS. A. Grafik Tanpa Tumpatan. B. Grafik dengan Tumpatan Fuji IX. C. Grafik dengan Tumpatan Ketac Molar.

Gambar 1,2,3,4 diambil dari laboratorium Metalurgi FT UI, 2005) 
Tabel Uji t dari Selisih Kandungan Unsur Fluor antara Email Gigi Tetap Muda Tanpa Tumpatan dan dengan Tumpatan Fuji IX dan Ketac Molar

\begin{tabular}{llcccc} 
Tumpatan & \multicolumn{1}{c}{$\Delta$} & Kisaran & $\mathrm{t}$ & $\mathrm{df}$ & $\mathrm{p}$ \\
& Rerata $\pm \mathrm{SB}$ & & & & \\
\hline Fuji IX & $2.09 \pm 0.75$ & $1.03-3.24$ & & & \\
Ketac Molar & $2.34 \pm 0.36$ & $1.08-0.96$ & & 20 & 0.065 \\
\hline
\end{tabular}

$\begin{array}{cc}\text { Keterangan : } \mathbf{t}=\text { Nilai Uji, } & \mathbf{S B}=\text { Simpang Baku } \\ \mathbf{p}=\text { Nilai Signifikan } & \mathbf{d f}=\text { degree of freedom } \\ & \Delta=\text { Selisih kandungan unsur fluor }(\%) \text { antara tanpa dan dengan tumpatan Fuji IX dan Ketac } \\ & \text { Molar }\end{array}$

